\title{
In situ reflection electron energy loss spectroscopy measurements of low temperature surface cleaning for Si molecular beam epitaxy
}

\author{
Shouleh Nikzad, Selmer S. Wong, Channing C. Ahn, Aimee L. Smith, \\ and Harry A. Atwater \\ Thomas J. Watson Laboratory of Applied Physics, California Institute of Technology, \\ Pasadena, California 91125
}

(Received 28 September 1992; accepted for publication 2 July 1993)

\begin{abstract}
In situ analysis of hydrocarbon desorption from hydrogen terminated $\mathrm{Si}(100)$ surfaces was performed in a silicon molecular beam epitaxy system, using reflection electron energy loss spectroscopy, in conjunction with conventional reflection high energy electron diffraction analysis. Measurements of $\mathrm{C} K$ edge core loss intensities demonstrate that this mothod is sufficiently sensitive to enable in situ analysis of hydrocarbon desorption at fractional monolayer coverages during low-temperature isothermal anneals. Hydrocarbon desorption was found to begin at $115^{\circ} \mathrm{C}$, and at $200^{\circ} \mathrm{C}$ complete desorption occurred within $10 \mathrm{~min}$. Hydrocarbon coverage was not measurably affected by operation of ionization gauge filaments during low temperature anneals, but was increased by transient outgassing of the sample holder, and its environs.
\end{abstract}

Low-temperature epitaxial growth capability on Si surfaces is important to many aspects of device and integrated circuit technology. Fabrication of structures with abrupt doping profiles, heterojunctions, ${ }^{1}$ metastable alloys, and growth on preprocessed very large scale integrated (VLSI) circuits $^{2}$ dictates that growth and processing temperatures be kept as low as possible. Such exacting requirements also have a significant impact on surface cleaning and treatment prior to epitaxial growth, and are incompatible with standard cleaning techniques based on native oxide desorption from silicon at temperatures above $\sim 800^{\circ} \mathrm{C}$. This has motivated development of cleaning procedures that inhibit oxide formation by silicon surface passivation with a hydrogen termination. Almost inevitably, some physisorbed hydrocarbons remain on the silicon surface following hydrogen termination, and removal of these adsorbates is a key step in rendering a surface suitable for growth. Most processes for hydrogen termination involve surface exposure to a liquid or gaseous hydrofluoric acid solution. A comprehensive study of oxygen and carbon coverage on $\mathrm{Si}$ surfaces treated by a spin coating in an HF/ethanol solution in a nitrogen ambient ${ }^{3}$ indicated gradual hydrocarbon desorption at $200^{\circ} \mathrm{C}$. Rapid sample heating to the growth temperature $\left(400-450^{\circ} \mathrm{C}\right)$ caused formation of silicon carbide, which is not removable at low temperatures. Subsequent successful epitaxial growth at $400^{\circ} \mathrm{C}$ provided a critical test of hydrocarbon desorption during the $200^{\circ} \mathrm{C}$ prebake. More recently, it was shown that a simple sample cleaning procedure consisting of chemical oxidation, followed by immersion in an aqueous HF solution prior to the $200^{\circ} \mathrm{C}$ prebake is sufficient for epitaxial growth at $370^{\circ} \mathrm{C}$. $^{4}$ Another surface analysis study of adsorption of various hydrocarbon types to HF-treated silicon surfaces followed by device growth on these surfaces has shown that semiconductor device quality is a strong function of growth and characterization environments. ${ }^{5}$

Ideally, hydrocarbon desorption would be verified by in situ analysis in the growth chamber immediately prior to growth. In this letter, we report the first quantitative measurements of hydrocarbon desorption from hydrogen- terminated $\mathrm{Si}(100)$ surfaces in a conventional molecular beam epitaxy (MBE) system with an in situ analysis technique, reflection electron energy loss spectroscopy (REELS). ${ }^{6,7}$ REELS is a powerful technique with long working distance which does not compromise the growth environment in a molecular beam epitaxy system, and which can yield compositional information with depth resolution and absolute detection limits which are comparable to those of x-ray photoelectron spectroscopy (XPS) and Auger electron spectroscopy (AES). The in situ quantitative measurements of hydrocarbon desorption for silicon surfaces mounted on a molecular beam epitaxy sample manipulator (ISA RIBER type) during different stages of in situ sample preparation for MBE growth are described here. This configuration allows the onset of hydrocarbon desorption to be determined, and allows direct, timeresolved measurements of contamination unique to the growth chamber.

The typical experimental configuration for REELS has been described elsewhere. ${ }^{6-8}$ Briefly; electrons from a 30 $\mathrm{keV}$ gun are scattered from the sample in the usual grazing incidence reflection high energy electron diffraction (RHEED) geometry, pass through a small aperture on the RHEED screen and are energy analyzed by a magnetic spectrometer. At $30 \mathrm{keV}$, electrons are strongly forward scattered ${ }^{6}$ which eliminates the requirement for positioning the spectrometer close to the sample (unlike XPS and AES). In these measurements, simultaneous RHEED and REELS data are obtained which detect surface morphology, crystallinity, and chemical composition. Typical parameters for the gun in the measurements in this letter are $30 \mathrm{keV}$ with $50 \mu \mathrm{A}$ emission current and about $0.5-2 \mu \mathrm{A}$ of sample current. The electron beam spot size on the sample was approximately $0.02 \mathrm{~cm} \times 2 \mathrm{~cm}$, yielding a sample current density of approximately $25 \mu \mathrm{A} / \mathrm{cm}^{2}$ and typical measurement times were 600-1000 s. The surface sensitivity of REELS is dependent on the incident angle of the electron beam and most of the measurements in this letter were performed with an incident beam angle of 5-10 mrad $\left(0.5^{\circ}\right)$. 
Although the core electron ionization cross scctions, and thus the measured core loss intensities, of low atomic number elements $(Z=1-15)$ are relatively large, these features are superimposed in an electron energy loss spectrum onto an exponentially decaying low loss background (due primarily to plasmon excitation). In order to quantify low levels of $\mathrm{C}$ coverage, on an $\mathrm{H}$-terminated $\mathrm{Si}$ wafer, simple background subtraction ${ }^{9}$ of the raw data is not appropriate. For these measurements, a standard second difference technique was used to extract the signal from the background in the energy loss spectrum. ${ }^{10}$ A reference sample consisting of a $1 \mu \mathrm{m}$ epitaxial film of $\mathrm{SiC}$ grown on $\mathrm{Si}(100)$, whose surface stoichiometry was independently measured by $\mathrm{x}$-ray photoelectron spectroscopy measure-. ments, was used to determine empirical $\mathrm{C} K(285 \mathrm{eV})$ and Si $L_{2,3}(99 \mathrm{eV})$ energy loss cross sections. Second difference $\mathrm{C} K$ energy loss spectra of the $\mathrm{SiC}$ sample were thus used as a reference for quantification of the $\mathrm{C} K$ intensity from adsorbed hydrocarbons on hydrogen-terminated $\mathrm{Si}$ wafers. ${ }^{11}$

$\mathrm{Si}(100)$ samples were prepared by alternate chcmical formation and removal of a surface oxide (the RCA cleaning). An oxide is formed in an $80^{\circ} \mathrm{C}$ 5:1:1 solution of $\mathrm{H}_{2} \mathrm{O}: \mathrm{NH}_{4} \mathrm{OH}: \mathrm{H}_{2} \mathrm{O}_{2}$ followed by a dip in a $1: 10$ solution of $48 \% \mathrm{HF}: \mathrm{H}_{2} \mathrm{O}$. The final step was to dip the Si wafer in the $\mathrm{HF} / \mathrm{H}_{2} \mathrm{O}$ solution to form a hydrogen terminated $\mathrm{Si}(100)$ surface. To control the nature of the hydrocarbon contamination, some of the samples were also rinsed with methanol after the immersion in the HF solution. The samples were immediately inserted into the MBE loadlock region and were transferred into the ultrahigh vacuum (UHV) growth chamber within 20-30 min of the final HF dip. The variation of $\mathrm{C}$ coverage on $\mathrm{Si}(100)$ surfaces with time was measured using in situ REELS. REELS data were first taken at room temperature. Subsequent data were collected at the prebake temperature $\left(100-200^{\circ} \mathrm{C}\right)$ at approximately $8 \mathrm{~min}$ intervals. After ten or twelve measurements at the prebake temperature, the wafer temperature was ramped at a rate of $12{ }^{\circ} \mathrm{C}$ per minute until $(2 \times 1)$ reconstruction of the $\mathrm{Si}(100)$ was observed $\left(400-430^{\circ} \mathrm{C}\right)$ using RHEED. REELS spectra were taken of the reconstructed surface and the $\mathrm{C}$ coverage was estimated. To minimize the effect of possible beam damage on the measurement, a new position on the sample was used for each subsequent measurement. In this case, nonuniform hydrocarbon coverage introduces a measurement error. To assess the degree of $\mathrm{C}$ coverage nonuniformity, REELS measurements were performed at room temperature on ten spots (each $2 \mathrm{~mm}$ apart) on a wafer. Figure 1 illustrates the variation of $C$ coverage with position on the wafer and indicates that the coverage varies by about $1.3 \%$ of a monolayer with measurement position.

Figure 2 illustrates the time variation of $\mathrm{C}$ coverage during isothermal REELS measurements at three different temperatures. In Fig. 2(a), a gradual reduction of $\mathrm{C}$ coverage is observed during the first $30 \mathrm{~min}$ at $115^{\circ} \mathrm{C}$. The $\mathrm{C}$ coverage falls rapidly to below our detection limit during the first $10 \mathrm{~min}$ at 150 and $200^{\circ} \mathrm{C}$, but an increase in $\mathrm{C}$ coverage is observable at later times $(\sim 50 \mathrm{~min})$. This rise

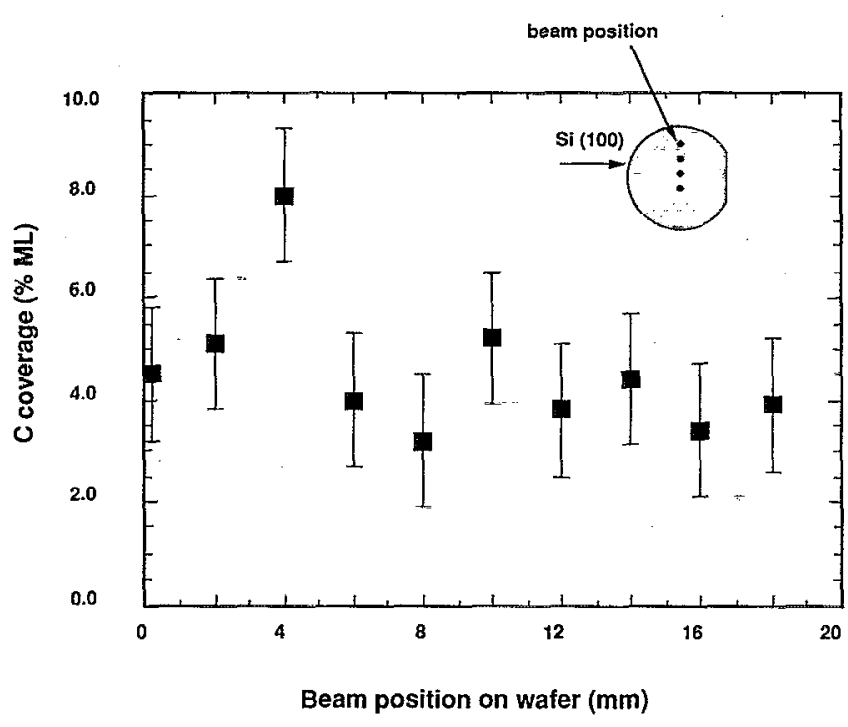

FIG. 1. Map of $\mathrm{C}$ coverage on a 2-in. cleaned $\mathrm{Si}(100)$ wafer which wafer was dipped in methanol following a RCA clean and an HF dip. REELS spectra were taken at room temperature to estimate the $\mathrm{C}$ coverage uniformity on the sample. The wafer was vertically translated $2 \mathrm{~mm}$ in each step to probe a new area on the wafer. The variation of $\mathrm{C}$ coverage along this wafer is within $1.3 \%$ of a monolayer.

in the hydrocarbon coverage is most likely due to outgassing of components in the UHV chamber which are unavoidably heated during the sample prebake (e.g., substrate holder). Notably, for samples prebaked at all the three temperatures in Figs. 2(a)-2(c), the $C$ concentration at $400^{\circ} \mathrm{C}$ is again negligible. Figure $2(\mathrm{~d})$ is a set of typical second difference spectra at various temperatures. Previous studies indicate that for temperatures between 200 and $400^{\circ} \mathrm{C}$, the surface hydrogen coverage of an HF-dipped $\mathrm{Si}(100)$ surface evolves continuously from a mostly dihydride termination to a monohydride termination. ${ }^{12,13}$ This is accompanied by a change in the surface reconstruction from $(1 \times 1)$ to $(2 \times 1)$. This would suggest that during thermal annealing at temperatures between 200 and $400^{\circ} \mathrm{C}$, the fraction of hydrocarbon coverage which was adsorbed in situ was adsorbed on a silicon surface with a mixture of dihydride and monohydride termination, but desorbed if the sample temperature is ramped slowly, as previously suggested. ${ }^{3}$

It is difficult to generalize about hydrocarbon desorption mechanisms since these are in principle dependent on hydrocarbon structure and molecular weight, and since the relative abundance of different species depends on the cleaning and growth environments and cleaning solutions. Some observations can be made about hydrocarbon desorption from hydrogen-terminated Si surfaces by quantifying time-dependent coverages. The apparent activation energy for hydrocarbon desorption in our experiments of $0.03 \mathrm{eV}$, is much smaller than the energy required to break chemical bonds between $\mathrm{C}$ and $\mathrm{Si}$, or $\mathrm{H}$ and $\mathrm{Si}$, confirming that the hydrocarbons are physisorbed on the Si surface.

Although we had taken precautions in our measurements to minimize electron beam-induced damage on the $\mathrm{H}$-terminated surfaces, we made independent measure- 

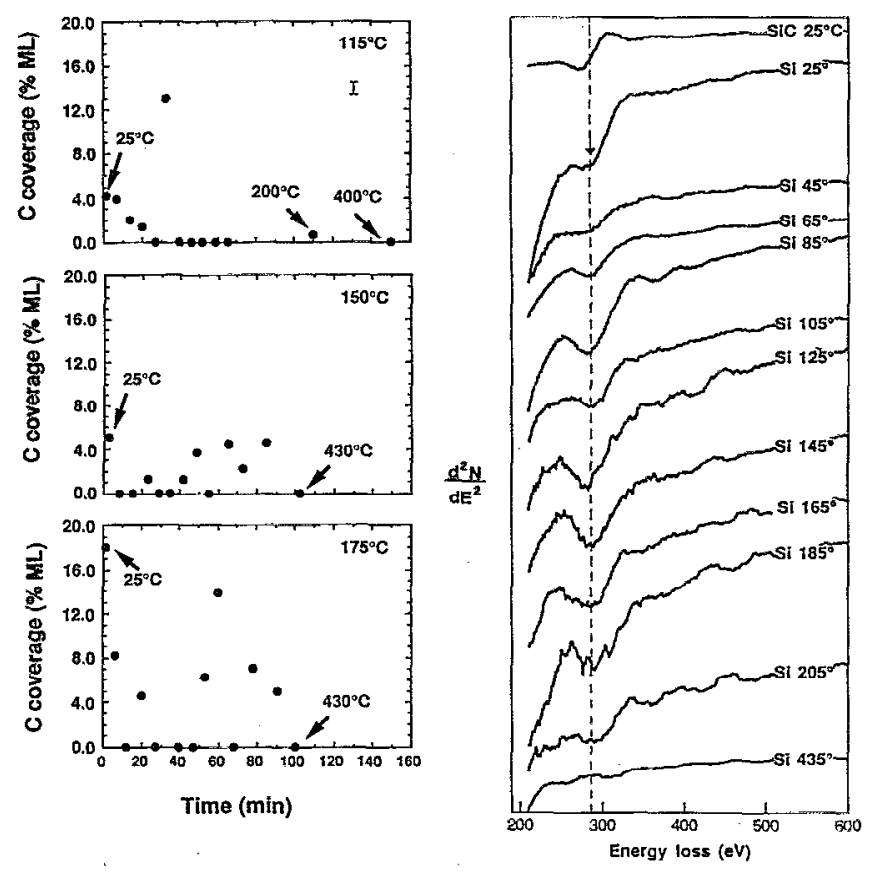

FIG. 2. (a)-(c) Isothermal measurements of $C$ coverage at 115, 150, and $175^{\circ} \mathrm{C}$, respectively. The wafer prebaked at $115^{\circ} \mathrm{C}$ was rinsed in methanol, following the HF immersion. The $\mathrm{C}$ coverage at room temperature gradually drops to zero within $30 \mathrm{~min}$ at $115^{\circ} \mathrm{C}$, whereas for 150 and $175^{\circ} \mathrm{C}$, the decline is sharp and in the first $10 \mathrm{~min}$. Since according to the first plot, the desorption of hydrocarbons is activated at $115^{\circ} \mathrm{C}$, the desorption of the hydrocarbons is complete by the time wafer temperature has reached 150 or $175^{\circ} \mathrm{C}$. A $2 \times 1$ reconstruction RHEED pattern is observed at $400-430^{\circ} \mathrm{C}$. The intermediate rise in the C coverage in the bottom two plots is attributed to outgassing from the unbaked surfaces (e.g., substrate block in the chamber). The final C coverage at $400^{\circ} \mathrm{C}$ is again negligible. (d) shows variation of typical second difference $\mathrm{C} 1 \mathrm{~s}$ spectra with temperature from the $\mathrm{Si}(100)$ surface. The $\mathrm{SiC}$ data is used as a reference and the arrow indicates the onset of the $C K$ ionization edge at $284 \mathrm{eV}$.

ments to assess the degree of beam influence on the $\mathrm{H}-\mathrm{Si}$ bond. Consecutive REELS measurements of C coverages were made for the same point on $\mathrm{Si}$ wafers at room temperature with a $30 \mathrm{keV}$ electron beam and $0.03 \mathrm{~mA} / \mathrm{cm}^{2}$ sample current density. No change in $\mathrm{C}$ surface coverage was observed after $20-50 \mathrm{~min}$ of irradiation. This finding is consistent with recent Auger studies ${ }^{14}$ of time evolution profiles of $\mathrm{O}$ and $\mathrm{C}$ on $\mathrm{H}$-terminated $\mathrm{Si}(100)$ surfaces, which reported an incubation time before $\mathrm{C}$ and $\mathrm{O}$ are detected on the $\mathrm{Si}(100)$ surface which increases with increasing beam energy. Our beam current density is lower than that work, and our irradiation times are lower by factors of 2 or 3 . Also, it was reported that the cross section of hydrogen desorption decreases by orders of magnitude with increasing electron energy. Given our higher incident electron energy of $30 \mathrm{keV}$ (as opposed to $2-5 \mathrm{keV}$ used in Auger measurements), and shorter irradiation times, it is not surprising that we do not observe significant beam-induced hydrocarbon desorption.

It is natural to suspect that hydrocarbon dissociation by hot filaments, such as an ionization gauge filament, is responsible for the contamination of the sample surface. So far, this has been suggested ${ }^{4}$ due to the quality of the epitaxial films grown. However, to separate this effect from other factors which could affect growth, we measured $\mathrm{C}$ coverage with the ionization gauge, which is in a line of sight to the substrate, on and off. The variation in the $\mathrm{C}$ coverage in these measurements were comparable to the spatial fluctuation in hydrocarbon coverage indicated in Fig. 1 and the coverages in the two cases were similar. These measurements indicate that the ionization gauge operation does not have a significant effect on the hydrocarbon adsorption.

We have performed in situ measurements of $\mathrm{C}$ coverage of RCA-cleaned and HF-dipped $\mathrm{Si}(100)$ surfaces in a molecular beam epitaxy growth chamber. We observed that hydrocarbon desorption is activated at $115^{\circ} \mathrm{C}$ and with the sensitivity of our measurements the coverage gradually drops to negligible levels after $30 \mathrm{~min}$. At the temperature that $(2 \times 1)$ reconstruction is observed in RHEED, C coverage is negligible provided that the sample is annealed at $\sim 115-200^{\circ} \mathrm{C}$ before heating to high temperature. We have demonstrated that the sensitivity of the REELS technique is sufficient to detect hydrocarbon coverages of $\sim 1 \%$ of a monolayer and since lower electron doses can be employed, REELS is a somewhat less destructive technique than Auger electron spectroscopy.

This work was supported by grants from NSF (DMR9202587) and the Caltech Consortium in Chemistry and Chemical Engineering. Use of $x$-ray photoelectron spectroscopy facilities of the Beckman Institute at Caltech and technical assistance of A. P. Rice is gratefully acknowledged.

${ }^{1}$ T. L. Lin, T. George, E. W. Jones, A. Ksendzov, and M. L. Huberman, Appl. Phys. Lett. 60, 1 (1991).

${ }^{2}$ M. E. Hoenk, P. J. Grunthaner, F. J. Grunthaner, R. W. Terhune, M. Fattahi, and H. Tseng, Appl. Phys. Lett. 61, 1084 (1992).

${ }^{3}$ P. J. Grunthaner, F. J. Grunthaner, R. W. Fathauer, T. L. Lin, M. H. Hecht, L. D. Bell, W. J. Kaiser, F. D. Schowengerdt, and J. H. Mazur, Thin Solid Films 183, 197 (1989).

'D. J. Eaglesham, G. S. Higashi, and M. Cerullo, Appl. Phys. Lett. 59, 685 (1991).

${ }^{5}$ S. R. Kasi, M. Liehr, P. A. Thiry, H. Dallaporta, and M. Offenberg, Appl. Phys. Lett. 59, 108 (1991).

${ }^{6}$ H. A. Atwater and C. C. Ahn, Appl. Phys. Lett. 58, 269 (1991).

${ }^{7}$ S. Nikzad, C. C. Ahn, and H. A. Atwater, J. Vac. Sci. Technol. B 10, 762 (1992).

${ }^{8}$ C. C. Ahn, S. Nikzad, and H. A. Atwater, Mater. Res. Symp. Proc. 208, 157 (1991).

${ }^{9}$ R. F. Egerton, Electron Energy Loss Spectroscopy in the Electron Microscope (Plenum, New York, 1986).

${ }^{10} \mathrm{R}$. Leapman, Transmission Electron Energy Loss Spectrometry in Materials Science, edited by M. M. Disko, C. C. Ahn, and B. Fultz (TMS, Warrendale, PA, 1992), Chap. 3.

${ }^{1 i}$ S. S. Wong, S. Nikzad, C. C. Ahn, A. L. Smith, and H. A. Atwater, Mater. Res. Soc. Symp. Proc. 259, 449 (1992).

${ }^{12}$ S. Maruno, H. Iwasaki, K. Horioka, S. T. Li, and S. Nakamura, Jpn. J. Appl. Phys. 21, 263 (1982).

${ }^{13}$ J. A. Schaefer, Physica B 170, 45 (1991).

${ }^{14}$ T. Hsu, S. Lin, B. Anthony, R. Qian, J. Irby, D. Kinosky, A. Mahajan, S. Banerjee, A. Tasch, and H. Marcus, Appl. Phys. Lett. 61, 580 (1992). 